Research, Society and Development, v. 9, n. 4, e120942929, 2020

(CC BY 4.0) | ISSN 2525-3409 | DOI: http://dx.doi.org/10.33448/rsd-v9i4.2929

\title{
Metodologia ativa na formação se engenheiros e as relações com Ciência e a Tecnologia
}

e a Sociedade

\section{Active methodology in training engineers and relations with Science And Technology and Society}

Metodología activa en ingenieros de formación y relaciones con la Ciencia Y La Tecnología y la Sociedad

Recebido: 25/02/2020 | Revisado: 02/03/2020 | Aceito: 11/03/2020| Publicado: 20/03/2020

Benerina Porfirio Branco

ORCID: https://orcid.org/0000-0003-3239-1715

Universidade Federal de Itajubá, Brasil

E-mail: benerina@gmail.com

Adilson da Silva Mello

ORCID: https://orcid.org/0000-0002-1966-3686

Universidade Federal de Itajubá, Brasil

E-mail: prof.adilsonmello@unifei.edu.br

\section{Resumo}

O presente artigo é originário de uma pesquisa sobre equipes de competição tecnológica de uma Universidade Pública do Sul de Minas tendo como objetivo analisar as relações entre Ciência e a Tecnologia e a Sociedade (CTS), metodologias ativas e formação de engenheiros dessa Universidade. O percurso metodológico contou com investigação teórica sobre o contexto histórico que configurou: as transformações político-econômicas dos anos 70 e suas implicações educacionais e de ciência e tecnologia; A pesquisa de campo realizou entrevistas qualitativas e realizou visitas às oficinas. Foram realizadas entrevistas individuais e uma grupal com alunos - grupo focal - e individuais com professores e coordenadores das equipes de competições. A forma de tratamento das entrevistas foi a análise de conteúdo de Bardin. A análise das entrevistas revelou que há resposta positiva nas falas dos alunos e professores quanto a uma maior aproximação entre a universidade e comunidade civil, de modo a gerar artefatos e processos voltados para populações mais vulneráveis. A grande questão seria 'como' trazer essas demandas sociais para a academia. Concluímos que os alunos se interessam em aplicar o conhecimento teórico que recebem na universidade na resolução de problemas reais, em trabalhar de forma colaborativa e interdisciplinar, usando a criatividade 
para construir artefatos e para resolver questões sociais e, neste sentido, atingimos do nosso objetivo que era analisar as relações entre CTS, metodologias ativas e formação de engenheiros em uma Universidade Sul de Minas Gerais.

Palavras-chave: Educação, ensino; Tecnologias; Metodologias ativas; CTS.

\section{Abstract}

The present article originates from a research on technological competition teams from a Public University in the South of Minas Gerais aiming to analyze the relationships between CTS, active methodologies and training of engineers from that University. The methodological path included theoretical research on the historical context that shaped: the political and economic transformations of the 1970s and their educational and scientific and technological implications; The field research carried out qualitative interviews and made visits to the workshops. Individual interviews and a group with students - focus group - and individual interviews with teachers and coordinators of the competition teams were carried out. The form of treatment of the interviews was the content analysis of Bardin. The analysis of the interviews revealed that there is a positive response in the speeches of students and professors regarding a closer relationship between the university and the civil community, in order to generate artifacts and processes aimed at more vulnerable populations. The big question would be 'how' to bring these social demands to the academy. We conclude that students are interested in applying the theoretical knowledge they receive at the university in solving real problems, in working in a collaborative and interdisciplinary way, using creativity to build artifacts and to solve social issues and, in this sense, we reached our goal that was to analyze the relationships between Science And Technology And Society (CTS), active methodologies and training of engineers at a University South of Minas Gerais.

Keywords: Education, teaching; Technologies; Active methodologies; CTS.

\section{Resumen}

El presente artículo se origina en una investigación sobre equipos tecnológicos de competencia de una universidad pública en el sur de Minas Gerais con el objetivo de analizar las relaciones entre CTS, metodologías activas y capacitación de ingenieros de esa universidad. El camino metodológico incluyó la investigación teórica sobre el contexto histórico que dio forma: las transformaciones políticas y económicas de la década de 1970 y sus implicaciones educativas, científicas y tecnológicas; La investigación de campo realizó entrevistas cualitativas e hizo visitas a los talleres. Se realizaron entrevistas individuales y un 
grupo con estudiantes (grupo focal) y entrevistas individuales con maestros y coordinadores de los equipos de competencia. La forma de tratamiento de las entrevistas fue el análisis de contenido de Bardin. El análisis de las entrevistas reveló que existe una respuesta positiva en los discursos de estudiantes y profesores con respecto a una relación más estrecha entre la universidad y la comunidad civil, a fin de generar artefactos y procesos dirigidos a las poblaciones más vulnerables. La gran pregunta sería "cómo" llevar estas demandas sociales a la academia. Concluimos que los estudiantes están interesados en aplicar los conocimientos teóricos que reciben en la universidad para resolver problemas reales, trabajar de manera colaborativa e interdisciplinaria, usar la creatividad para construir artefactos y resolver problemas sociales $y$, en este sentido, alcanzamos nuestro objetivo de que fue analizar las relaciones entre Ciencia Y La Tecnología Y La Sociedad (CTS), metodologías activas y la capacitación de ingenieros en una Universidad del Sur de Minas Gerais.

Palabras clave: Educación, enseñanza; Tecnologías; Metodologías activas; CTS.

\section{INTRODUÇÃO}

O presente artigo é originário de uma pesquisa sobre equipes de competição tecnológica de uma universidade pública de Minas Gerais e trata da relevância da aprendizagem ativa na contemporaneidade. A Universidade Federal de Itajubá (UNIFEI) é uma universidade centenária que possui atualmente mais de vinte cursos em sua grade, a grande maioria de engenharia. Fundada em 1913 como Instituto Eletrotécnico e Mecânico por Theodomiro Santiago, que teve como escopo criar "um estabelecimento para a formação de engenheiros, onde o ensino fosse voltado para a realidade prática e o ambiente de trabalho fosse tão aproximado quanto possível da vida real." (Guimarães,1999, p.91). Mesmo que na realidade muitas vezes esse princípio tenha sido esquecido, na teoria ele é frequentemente lembrado por professores e ex-alunos como se compusesse o "DNA" da escola. Em meio às investigações a pesquisa identificou a ocorrência das metodologias ativas nos trabalhos das equipes de competição. Metodologias ativas correspondem a um conjunto de estratégias de ensino/aprendizagem em que o aluno sai de uma condição passiva e torna-se protagonista na construção do conhecimento tendo o professor como um facilitador.

A partir da Revolução Tecnológica desencadeada a partir dos anos 70 os espaços passaram a ser influenciados, ainda que de forma e em velocidades diferentes por ciência, técnica e informação exigindo novas habilidades dos profissionais e dos indivíduos em geral. No campo educacional formou-se uma geração digital e multitarefa incapaz de ficar sentada 
ouvindo um professor por muito tempo e que não vê sentido em memorizar informações - as quais logo serão esquecidas - disponíveis nas pontas dos dedos. Paralelamente à Revolução Tecnológica, a crise do capitalismo provocou o advento da política econômica neoliberal e do modelo de produção toyotista que se espalharam pelo globo desencadearam desemprego e precarização do trabalho. A partir do momento em que a educação passou a ser vista como insumo para a economia, assumiu uma perspectiva tecnicista e suas premissas se voltaram para a preparação de uma mão de obra adequada às demandas desse novo mundo do trabalho marcado pelo desemprego. Pretende-se evidenciar a relevância das metodologias ativas como um catalizador entre as circunstâncias políticas e socioeconômicas da contemporaneidade.

O percurso metodológico contou com investigação teórica sobre o contexto histórico que configurou: as transformações político-econômicas dos anos 70 e suas implicações educacionais e de ciência e tecnologia; a Revolução Tecnológica e a chamada geração dos nativos digitais. No campo empírico foram realizadas entrevistas individuais e uma grupal com alunos - grupo focal - e individuais com professores e coordenadores das equipes de competições. Também foram feitas visitas às oficinas onde as equipes constroem seus artefatos tecnológicos.

\section{CONTEXTUALIZAÇÃO}

\section{Neoliberalismo, Toyotismo e Revolução Tecnológica}

A segunda metade do século XX foi marcada por extensas transformações no mundo do trabalho em função da crise capitalista dos anos 70 e da Revolução Tecnológica modificando a política econômica e os sistemas de produção industrial de forma global. Os anos do entre guerras assistiram a uma onda geral de intervencionismo do Estado na economia - por essência - na URSS stalinista e nos regimes capitalistas totalitários da Europa - e por conta da crise - na democracia liberal de Roosevelt. Nos EUA, o Welfare State e o New Deal, configuraram o Estado de Bem-Estar keynesiano, garantindo aos cidadãos, direitos sociais como o pleno emprego que aliado ao modelo fordista de produção em massa visaram a recuperação da crise de 1929. Após a $2^{\mathrm{a}}$ Guerra, em função da reconstrução dos países devastados pelo conflito o Estado assumiu a responsabilidade pelos cidadãos em suas implicações socioeconômicas. O Welfare State chegou ao apogeu nos anos 60, porém na década de 70 começou a entrar em crise evidenciando que sua sobrevivência está vinculada ao nível de desenvolvimento econômico do país onde se aplica. E assim, a crise do capitalismo 
solapou as bases do Welfare State que paulatinamente foi sendo substituído por políticas de orientação liberal configurando o neoliberalismo.

As origens teóricas do neoliberalismo podem ser encontradas nos anos 40, em " $\mathrm{O}$ Caminho da Servidão" de Hayek, mas foi após a crise da década de 70 que ele passou a ser considerado como alternativa para recuperar o capitalismo global. O Estado passou a ser responsabilizado pela eclosão da crise por ter assumido demasiados gastos sociais. Portanto, será substituído em grandes proporções pelo mercado configurando o que se convencionou chamar de Estado mínimo. O desmonte do Estado de Bem-Estar e início do neoliberalismo remete principalmente à Inglaterra de Thatcher e aos EUA de Reagan e dentre seus principais elementos está a flexibilização das leis trabalhistas. Ao final da década de 80 o Consenso de Washington irá prescrever o remédio neoliberal para a 'doença' da economia latinoamericana. A partir de então, o neoliberalismo irá definir todas as políticas implementadas no continente com efeitos diretos nas políticas públicas de modo geral e no mundo do trabalho tendo como resultado mais atroz o desemprego e a precarização do trabalho em um mundo de economia globalizada.

Se a reestruturação do pós-guerra trouxe estados intervencionistas, foi também no pósguerra que se desenvolveu um novo modelo de produção industrial no Japão. O toyotismo surgiu como alternativa ao modelo fordista norte-americano para que o país pudesse recuperar sua economia após a catástrofe gerada pela $2^{\text {a }}$ Guerra Mundial. Durante os anos 1950 e 60 engenheiros japoneses desenvolveram um sistema de produção adequado à realidade de seu país nas fábricas da montadora de automóveis Toyota. Em oposição à produção em massa fordista, os japoneses idealizaram um sistema de produção flexível, ou seja, produção adequada à demanda e que também prevê redução dos estoques; diversificação dos produtos fabricados e automatização de etapas da produção visando reduzir desperdícios e evitar superprodução. Esse toyotismo ou "just in time", exigiu maciço investimento tecnológico nos meios produtivos e também uma mão de obra qualificada e multifuncional capaz de assumir diferentes funções, causando drástica redução na oferta de empregos. Principalmente a partir da década de 70 o toyotismo começou a ser adotado em outros países. A crescente adoção do sistema de produção flexível nas indústrias com o consequente acúmulo de funções dos trabalhadores empregados impulsionaram o desemprego.

Finalmente a Revolução Tecnológica também chamada $3^{\mathrm{a}}$ Revolução Industrial, engendrou, segundo Milton Santos (2001), um meio Técnico-Científico-Informacional caracterizado pela utilização de tecnologias de informação em que os fluxos ocorrem de modo instantâneo por meio de uma rede mundial de computadores. A união entre a ciência e a 
técnica é fortalecida graças aos recursos da informática e da globalização sob a égide do mercado. Com isso as transações econômicas e os negócios expandiram-se ao mesmo tempo em que a "aldeia global" de McLuhan (1968) encolheu. O meio técnico-científicoinformacional modificou as relações sociais, o trabalho, o lazer, o consumo, as noções de tempo e espaço e a educação. Entre 1995 e 2010, emergiu a chamada Geração "Z”, os nativos digitais, extremamente familiarizados com computadores, internet e smartphones. No século XXI, conforme Seemiller \& Grace (2016) a Geração "Z" chegou à universidade e tem características, motivações, habilidades, preocupações e estilos de aprendizagem diferentes das gerações anteriores. Para essas autoras, a Geração Z cresceu em um cenário de recessão e não tem muitas ilusões sobre suas perspectivas de emprego sendo mais empreendedora, inovadora, independente, aberta a economia de compartilhamento e mais tolerante. A Revolução Tecnológica forjou novas profissões ligadas às telecomunicações e informática, mas extinguiu diversos postos de trabalho em função da automação nos três setores da economia. $\mathrm{O}$ avanço da informalidade registrado nos anos 90 - vide Gráfico 1 - é uma das evidências do desemprego engendrado por todas as transformações relatadas anteriormente, neoliberalismo, toyotismo e automatização.

\section{Gráfico 1 - Grau de informalidade no mercado metropolitano (em \%).}

EVOLUÇãO DO GRAU DE INFORMALIDADE

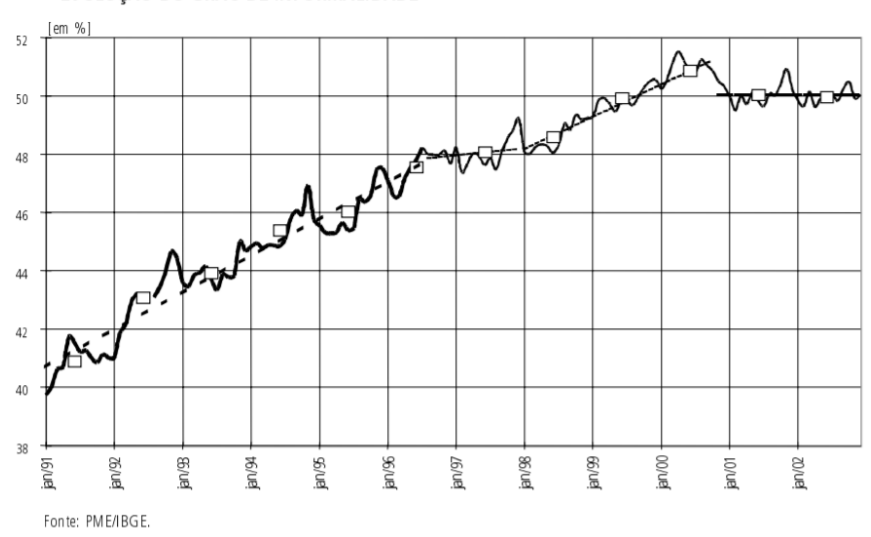

Fonte IBGE/PME 
O gráfico 1 evidencia um aumento no grau da informalidade nos anos 90 conforme o IBGE.

\section{EFEITOS DO CONTEXTO POLÍTICO ECONÔMICO NAS POLÍTICAS EDUCACIONAIS E DE CIÊNCIA E TECNOLOGIA}

\section{Política Educacional}

A chegada dos militares ao poder em 1964 representou, segundo Ribeiro (1992), a implantação de uma política educacional tecnicista no país, visando adequar o ensino nacional ao projeto "Brasil-Potência" atrelando os objetivos da política educacional brasileira aos interesses do capital internacional. A implementação da Lei no 5.692 de 1971, oficializou essa concepção tecnicista como modelo pedagógico fortalecendo o ensino voltado para tecnologias e restringindo as ciências humanas e o ambiente para o posicionamento crítico. "Inspirada nos princípios de racionalidade, eficiência e produtividade, a pedagogia tecnicista advogou a reordenação do processo educativo de maneira a torná-lo objetivo e operacional.” (Saviani, 2011, p. 381).

O fundamento teórico dessa concepção foi a Teoria do Capital Humano idealizada por Schultz (1973) nos anos 50, propondo a qualificação da mão-de-obra através da educação, como um dos mais importantes meios para incremento do lucro. Ao educar-se o ser humano estaria agregando valor a si próprio de modo a servir adequadamente ao mercado. Nessa perspectiva os investimentos em educação são vistos como insumo para o desenvolvimento econômico, o aluno se torna instrumento do governo para suprir as necessidades da economia e o professor um técnico a fim de atender às exigências de uma sociedade industrializada. A Teoria do Capital Humano transfere para o âmbito individual os problemas da inserção social, do emprego e do desempenho profissional.

Conforme visto, a crise dos anos 70 engendrou mudanças profundas na economia mundial impactando todas as esferas da vida moderna, inclusive a educação. No Brasil, segundo Saviani (Idem), a Lei de Diretrizes e Bases de 1996 foi o marco da influência neoliberal produtivista na educação, adequando o ensino às demandas do mercado global. Se na fábrica o fordismo foi sendo substituído pelo toyotismo, exigindo profissionais criativos, flexíveis e inovadores, na escola surge o neotecnicismo. A pedagogia 'neotecnicista' visa formar alunos dinâmicos, possuidores de diversas competências e habilidades para que sejam multifuncionais. Individualistas, mas que ao mesmo tempo saibam trabalhar em equipe. Também que sejam empreendedores, tanto no sentido de buscar capacitação constante, como 
no sentido de abrir seu próprio negócio, pois não há emprego para todos. Assim a partir dos anos 80 e 90 as definições da Teoria do Capital Humano foram ressignificadas: se antes o trabalhador buscava se qualificar enquanto o Estado de Bem-Estar buscava garantir o pleno emprego, nessa fase do capitalismo a economia convive com altas taxas de desemprego e subemprego, terceirização, trabalho informal, dentre outras formas de precarização.

\section{A Política de Ciência, Tecnologia e Inovação}

Se no Japão o pós-guerra foi o cenário para a gestação do toyotismo, nos EUA foi o contexto em que ocorreu a estruturação de sua Política de Ciência e Tecnologia (PCT). Segundo Motoyama (2004) dada a posição hegemônica assumida pelos EUA no pós-guerra, sua PCT transformou-se no modelo para atividades de pesquisa e desenvolvimento (P\&D) que se irradiou para outros países. É fato que a aliança governo-comunidade científica consolidada nos Estados Unidos nesse contexto, verificou-se inclusive na URSS stalinista mediante a competição tecnológica gerada pela Guerra Fria. Contudo, o relatório publicado por Vannevar Bush em 1945, "Ciência, a Fronteira Sem Fim”, tornou-se uma obra seminal no sentido de consolidar a pesquisa científica em tempos de paz estabelecendo uma relação entre pesquisa, bem-estar econômico e segurança, inspirando os parâmetros da pesquisa e desenvolvimento (P\&D) no mundo.

Desde então, a PCT de cada país passou por transformações, mas segundo Oliveira (2014) nos anos 70, com a emergência do neoliberalismo os pilares do inovacionismo como foco das PCT foram lançados nos países centrais. Ainda que Schumpeter tenha pioneiramente concebido inovação como invenção que gera rendimentos, a publicação da obra The Economics of Industrial Innovation, de Freeman, em 1974 foi o difusor desse conceito. Nos anos 80 o conceito de inovação passa a constituir a essência das PCTs dos governos que substituíram o Welfare State pelo neoliberalismo. Conforme Oliveira (2018) o inovacionismo é uma perspectiva que vê a produção de inovações como objetivo básico da pesquisa científica e a inovação como uma invenção rentável, ou seja, lucrativa. No final dos anos 80 , após o Consenso de Washington esse inovacionismo passa a incorporar também a PCT dos países periféricos. No Brasil, o Marco Legal da Ciência, Tecnologia e Inovação visou fomentar a produção científica acelerando a relação entre entes públicos e privados através de incentivos financeiros e fiscais. Multiplicaram-se as incubadoras de empresas nas universidades e parcerias público-privadas aproximando a academia do setor produtivo. A criação dos Fundos Setoriais e a destinação de metade dos programas da FINEP estar 
direcionada a promover a inovação empresarial são apenas algumas evidências desse incremento conforme o Gráfico 2.

Gráfico 2: Execução orçamentária do FNDCT/Fundos Setoriais (1999-2005).

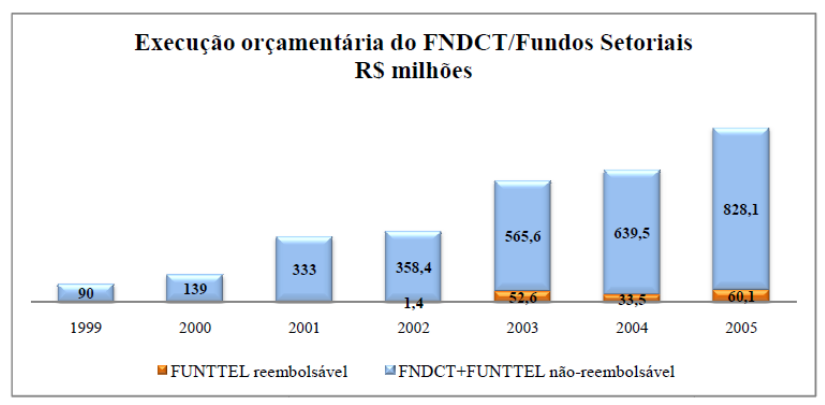

\section{Fonte: FNDCT/FINEP.}

O termo inovação vem adquirindo novos complementos ao longo do tempo. Nos anos 90, Christensen publicou "O $\underline{O}$ Dilema da Inovação", onde lançou a teoria de Inovação Disruptiva afirmando que há inovações que quebram paradigmas de forma diferenciada. Por exemplo, a invenção do automóvel no final do século XIX, constitui grande inovação em relação ao transportes de tração animal. Contudo, a inovação disruptiva ocorreu com a invenção do Ford T, o qual juntamente com a produção em massa diminuiu os custos dos automóveis impulsionando o consumo e transformando radicalmente os padrões de transporte no planeta.

\section{COMPETIÇÕES ACADÊMICAS COMO UMA METODOLOGIA ATIVA}

\section{Metodologias Ativas}

Nas últimas décadas as metodologias ativas (Konopka, 2015; Brekelmans, 2000; Van Hout-Wolters, 2000), o conjunto de estratégias de ensino-aprendizagem onde o aluno é protagonista e o professor um facilitador, estão em alta. Diante de uma geração digital e multitarefa incapaz de ficar sentada ouvindo um professor por muito tempo e que não vê sentido em memorizar informações - que logo serão esquecidas - e que estão disponíveis nas pontas dos dedos a sala de aula precisa ser reinventada. As Metodologias Ativas tiram o aluno de uma posição passiva tornando-o responsável pela construção de conhecimento e o professor atua como um mentor ensinando o aluno a "aprender a aprender", através de estratégias como aprendizagem por projetos, aprendizagem baseada em problemas e sala de aula invertida. Em uma perspectiva política, artigo de Ponsa (2009) refere-se às metodologias ativas como instrumento eficaz ao projeto europeu de tornar-se a "economia do conhecimento mais competitiva do mundo", visando atrair os melhores estudantes e focar a aprendizagem no 
que é relevante para o mercado global. Além disso, as metodologias ativas permitem absolutamente o alargamento do espectro de aprendizagem possibilitando a inclusão de temáticas sociais na proposição dos trabalhos. Artigo de Santos (2017) alega que uma possibilidade de incitar o pensamento crítico e reflexivo no engenheiro em atuação é por meio do engenheiro em formação, a pesquisa infere então, que mediante metodologias ativas o estudante de engenharia pode se envolver com questões reais de desigualdade e exclusão vivenciando na prática a complexidade da sociedade contemporânea.

$\mathrm{Na}$ base teórica das metodologias ativas estão Dewey o educador pioneiro em defender que o ensino deveria dar-se pela ação e não pela instrução e Piaget propondo uma aprendizagem significativa, na qual se deve aprender de forma autônoma e participativa, a partir de situações e problemas reais.

Evidentemente há desafios diante da adoção dessas estratégias, inclusive porque constantemente o mundo pedagógico é surpreendido por alguma teoria, tendência ou modismo apresentado como uma como panaceia diante dos complexos problemas na educação. Além disso, professores alegam que não podem garantir o cumprimento do programa, da aprendizagem ou da avaliação dado o caráter muito "livre" dessa prática pedagógica. Muitos alunos a rejeitam devido à exigência de um envolvimento maior das metodologias ativas. Certamente também há temores por parte de professores diante do inusitado, da situação constante de vulnerabilidade desse professor diante de uma classe mais independente e autônoma, a típica geração "Z”, com smartphone nas mãos e questionamentos na mente. Entretanto, os resultados da pesquisa teórica e as falas dos entrevistados falarão por si.

\section{Competições Tecnológicas e Startup Weekends}

$\mathrm{Na}$ virada do século XX para o XXI multiplicaram-se os eventos de competição acadêmica, sejam as tradicionais olimpíadas de conhecimento, passando pelos modernos Hackathons, maratonas de programação e empreendedorismo ou as competições tecnológicas aqui tratadas. A pesquisa inferiu que a proliferação dessas competições na atualidade reflete as novas demandas do mundo do trabalho que devido aos altos índices de desemprego, terceirização e trabalho informal requer alunos preparados para ambientes criativos, competitivos, inovadores e empreendedores. Entretanto se buscou também razões mais específicas para a grande atração exercida pelas competições entre os alunos através de pesquisa empírica. 
Segundo o professor Bruno Souza, coordenador geral dos Projetos de Competição Tecnológica da UNIFEI, a primeira equipe de competição formou-se na universidade em 1998 e atualmente há treze equipes trabalhando. Foram entrevistados além do professor Bruno, o professor Antônio Ancelotti, coordenador da equipe Ex Machina, que constrói próteses humanas, o professor Fábio Fowler, criador do Centro de Empreendedorismo e a professora Juliana Caminha, atual Diretora do Centro de Empreendedorismo e Inovação (CEU), todos da UNIFEI. Para o professor Bruno, as atividades nas equipes de competição promovem o desenvolvimento de habilidades e competências inexistentes nos currículos de engenharia, mas que fazem parte do dia a dia de um engenheiro como negociar, realizar transações financeiras, importar materiais, lidar com questões jurídicas, sociais, ambientais, biomédicas, éticas e culturais. Segundo ele, o que atrai os alunos de engenharia para as competições são as aulas práticas na oficina: "desenvolver equipamento, quebrar a cabeça, fazer um motor funcionar, resolver problemas reais na hora. Aí está o espírito da UNIFEI desde Theodomiro Santiago". O professor Ancelotti afirmou que quando se pede um trabalho na sala, mesmo que seja prático, o envolvimento dos alunos é diferente de quando estão nas equipes de competição. Ele acredita que o fato de os alunos serem os gerentes e terem uma estrutura hierárquica estabelecida por eles mesmos, bem como terem liberdade para escolhas e decisões é que os motiva. Para a professora Juliana Caminha, responsável pelo CEU, que atualmente incorpora o Núcleo de Inovação Tecnológica (NIT) da universidade, a UNIFEI possui uma comunidade acadêmica muito empreendedora. Afirmou que o que os alunos dos projetos de competição fazem nas oficinas vai muito além do que o que eles fazem dentro da sala de aula e acrescentou que geralmente são esses alunos que depois vão criar as startups no CEU porque adquiriram experiência em desenvolver projetos até à concretização e em gerenciar recursos. Assegurou que grande parte das startups de maior sucesso, especialmente na parte de tecnologia, são dos meninos que saíram da garagem (oficinas) e que por isso, tenta estar mais próxima deles na garagem, mas que eles a expulsam (risos) porque não querem professores lá. Eles querem estar sozinhos e ter o professor como um parceiro, o que ela acha positivo, sensacional. Argumentou que são projetos complexos e realizados com poucos recursos o que instiga a criatividade e o empreendedorismo nos alunos. Além disso, segundo ela, esses projetos geram um autoconhecimento fundamental para o desenvolvimento profissional. Exemplificou relatando que os alunos da equipe de combate de robôs (Uai!rrior) sabem que a mecânica deles é imbatível então investem fortemente na integração da eletrônica com essa mecânica. A equipe de drones (Black Bee) sabe que o grande diferencial deles é o conhecimento sobre programação e não sobre o design dos drones, então eles se 
tornaram experts no desenvolvimento do software para tornar o drone autônomo, e o que eles fazem a maioria dos professores não faria, segundo ela. Declarou que às vezes pensa em buscar mais recursos para os alunos, mas sempre repensa quando constata que os meninos do Uirá (equipe que constrói aeronaves) sabem mais de mecânica dos fluidos do que muito professor porque eles desenvolveram sozinhos os conhecimentos de dinâmica de fluidos para asas a um nível em que muitos professores não podem mais ajudá-los. E concluiu dizendo que por serem tão criativos e empreendedores no sentido tecnológico, muitos passam a querem empreender no sentido de business mesmo, e aí quando eles vão para o CEU os projetos se desenvolvem muito mais facilmente devido a essa experiência, de onde surgem muitas startups de impacto.

Ainda segundo a professora Juliana, o CEU foi idealizado pelo professor Fábio Fowler, o qual inconformado com o fato de ter saído da universidade despreparado para a realidade da engenharia e menos ainda para empreender, voltou para a academia como professor com o foco em preparar os alunos para a realidade do mercado. Ele é responsável pela implantação de vários projetos de aprendizagem prática como o Startup Weekend e o Hacklab, pela inclusão de disciplinas voltadas para o empreendedorismo nas grades curriculares e pela aplicação empírica de pedagogias ativas. Defende que o protagonismo dos alunos no processo ensino/aprendizagem é fundamental para que se formavam na universidade melhor preparados para o mercado de trabalho, capazes de atuar de maneira proativa e transversal, e desenvolvendo habilidades como autonomia, liderança, cooperação, criatividade e resiliência.

Os resultados das entrevistas com os alunos ao serem indagados sobre o que explica a grande adesão às competições tecnológicas, estão representados no Gráfico 3 e os entrevistas serão identificados por letras para sua privacidade. O gráfico demonstra que os trabalhos nos finais de semana e férias se justificam pela oportunidade de aplicar o conhecimento teórico e encarar problemas reais e inusitados, poder trabalhar em equipe e desenvolver a sociabilidade, e pela autonomia para criação e decisão.

\section{Gráfico 3 - Atrativos dos projetos especiais.}

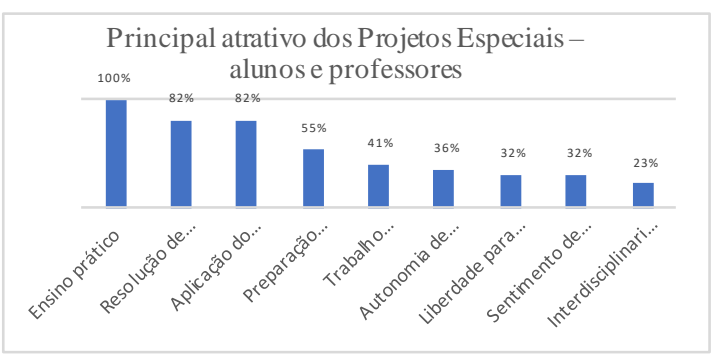




\section{Fonte: Autora.}

Segundo o entrevistado E1, apesar de existirem muitas aulas de laboratório no curso de engenharia, os processos e ambientes são controlados e o professor estabelece um roteiro para que todo mundo consiga seguir e ter os mesmos resultados. Nas oficinas onde desenvolvem os artefatos para as competições, as coisas geralmente não saem como se espera. É preciso "quebrar a cabeça" para resolver problemas inusitados. Então, se aprende de verdade. E2 afirmou que a oficina é o ambiente onde você pode falar: "Peguei todo o conhecimento que adquiri até agora e vou botar em prática. Vou dar uma finalidade para isso!”. Segundo E7 “o trabalho na oficina é muito legal não é como na aula onde já pesquisa e vai aprendendo por si só”. Segundo E3 os desafios financeiros para aquisição de materiais, por exemplo, são arrecadados pela equipe de marketing e gestão através de rifas, eventos, busca de patrocinadores. Aluno do curso de Engenharia Eletrônica afirmou que por ser o Diretor de Marketing da equipe, teve que adquirir conhecimentos e desenvolver habilidades que estão fora de sua "zona de conforto" em um trabalho interdisciplinar e que envolve questões sociais e éticas. Todos afirmaram que os professores são consultados quando necessário, mas as decisões são tomadas pelos alunos e que a oportunidade e o prazer de pôr a "mão na massa" e "aprender fazendo" está no topo da atração pelos projetos de competição. Importante destacar que o item "problemas reais", segundo mais apontado pelos alunos envolve não apenas problemas técnicos, mas também questões sociais, de exclusão, de desigualdade, questões éticas e ambientais.

Importante destacar que a questão do "ensino prático" não foi levantada pela pesquisadora nas perguntas, mas emergiu das respostas dos entrevistados. Também é necessário colocar que nenhum professor se referiu aos projetos de competição tecnológica e Startup Weekends como aplicação de metodologias ativas, mas como atividades extracurriculares eficazes no sentido de preparar melhor o aluno para a vida profissional e o mercado. Entretanto, na concepção da pesquisadora trabalhos pedagógicos que oportunizam um ambiente onde se aprende na prática, de forma interdisciplinar, os alunos são protagonistas e os professores são tutores, constituem uma metodologia ativa.

\section{AS METODOLOGIAS ATIVAS COMO UM CATALIZADOR}

Na segunda metade do século XX a emergência do capitalismo neoliberal, do sistema de produção toyotista e da Revolução Técnico-Científico-Informacional aplicada à produção 
agropecuária, industrial e dos serviços, varreu consideráveis postos de trabalho ao redor do mundo. $\mathrm{O}$ ambiente técnico-científico-informacional modificou as relações sociais e as noções de tempo e espaço. Diante dessa metamorfose surgiram os nativos digitais familiarizados com tecnologia, recessão e desemprego e, portanto, mais propícios a serem independentes, competitivos e empreendedores. Verificou-se que em função desse novo contexto político, econômico e tecnológico, nos anos 90 ocorreram mudanças nas políticas educacionais e de ciência e tecnologia visando ajustá-las às novas exigências da economia global, configurando um modelo neotecnicista para a educação e inovacionista para ciência e tecnologia. Para Braga (2020), o papel do professor será mediar o processo de ensinoaprendizagem, deixando de lado o status quo da prática docente estabelecida e rompendo com a perspectiva de um ensino de transmissão de conhecimentos numa relação vertical professor/aluno privilegiando, então, processos de aprendizagem que desenvolvam a criatividade e a colaboração.

\section{Figura 1 - Metodologias ativas.}

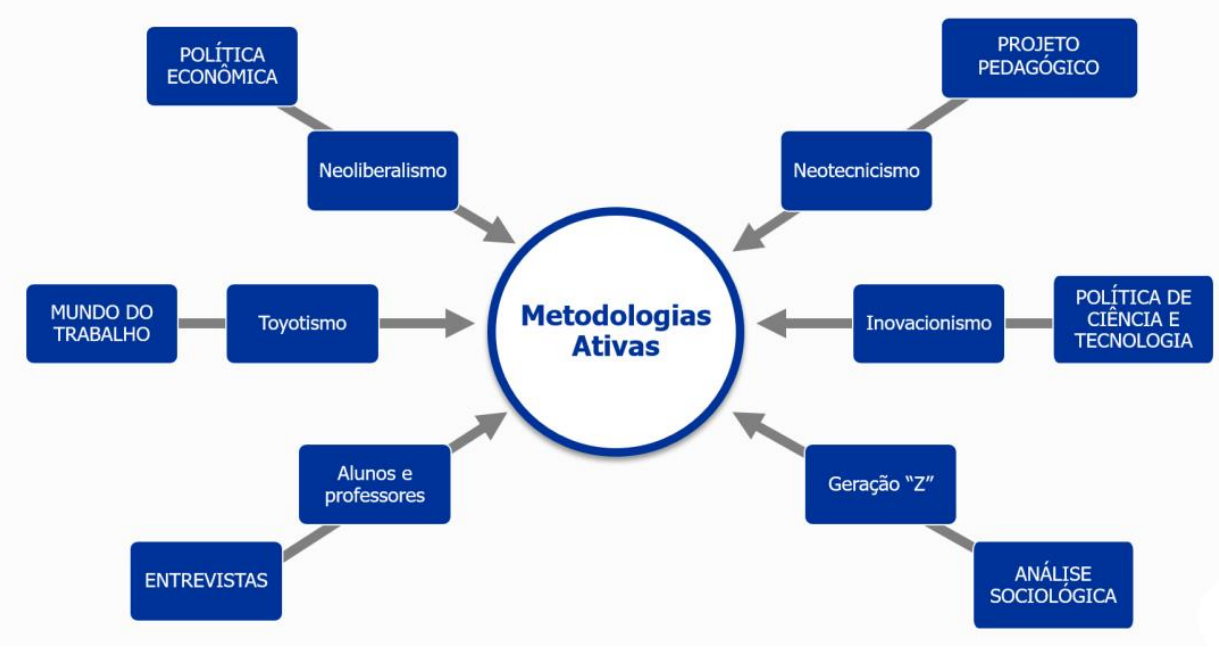

Fonte: Elaborada pela autora.

Para atender um mercado altamente competitivo e recessivo a escola deveria formar o aluno para ser possuidor de diversas competências e habilidades, criativo e empreendedor. Para que o Brasil tivesse algum lugar ao sol na sociedade do conhecimento do novo século que se aproximava, a PCT brasileira tornou-se Política de Ciência Tecnologia e Inovação. Dessa forma foi promovida a articulação entre o inovacionismo, o neotecnicismo e o toyotismo atrelados ao neoliberalismo. 
Paralelamente a essas transformações, a pesquisa constatou que na virada do século XX para o XXI a costura do tecido formado pelos contextos político, econômico, pedagógico e cultural evidenciaram uma convergência no sentido da aprendizagem pela prática. Especificamente no caso da universidade estudada, há uma base histórico-cultural de formar engenheiros "para pôr a mão na massa" que emerge das falas de alunos e professores nas entrevistas. Todavia, observa-se que a aprendizagem prática emergiu como um catalizador não apenas nas falas dos entrevistados, mas também entre as demandas política, econômica, pedagógica e sociológica nesse início de século.

\section{CONSIDERAÇÕES FINAIS}

A identificação dessa convergência para a aprendizagem prática não significa uma visão simplista da realidade diante da complexidade dos problemas detectados. Evidentemente não há uma coincidência nisso tudo, mas uma convergência deliberada evidenciando que neoliberalismo é uma doutrina que ultrapassa o espectro econômico.

Há que se buscar alternativas, mas esse não é o escopo desse artigo e sim, evidenciar a relevância da aprendizagem ativa como um catalisador entre as diversas e complexas demandas da contemporaneidade que emergem do mundo do trabalho marcado pelo desemprego e precariedade do trabalho cotidiano e da sociedade técnico-científicoinformacional em meio ao capitalismo neoliberal.

A despeito dos desafios desse contexto, atestou-se o ensino/aprendizagem por meio de metodologias ativas não só atende as demandas desse novo mundo do trabalho competitivo, mas tem correspondência com as características de uma geração nativa digital que rejeita passividade e rotina e se identifica com um ambiente multitarefa. Por meio das entrevistas constatou-se que os alunos se interessam em aplicar o conhecimento teórico que recebem na universidade na resolução de problemas reais, em trabalhar de forma colaborativa e interdisciplinar, usando a criatividade para construir artefatos e para resolver questões sociais.

A grande questão é integrar as demandas sociais aos interesses de pesquisa dos pesquisadores da referida instituição. Quando perguntados sobre demandas sociais, os mesmos apresentam ideias compatíveis com as demandas, o que não ocorre de modo espontâneo. As relações entre CTS, metodologias ativas poderá acontecer de modo efetivo quando a Universidade colocar em foco as necessidades das camadas sociais menos favorecidas com oferta de tecnologias sociais para gerar renda e transformar atividades e resultados dessas camadas sociais. O uso de metodologias ativas por si só não resolve as 
questões de incorporação de demandas sociais, mesmo que latentes no imaginário dos alunos envolvidos em projetos.

O presente artigo percebe limitações quanto a busca de respostas mais eficazes para se estabelecer essas relações. Propomos uma pesquisa comparativa sobre processos de formação de Engenheiros e suas relações com a CTS em Universidades Publicas do Sul de Minas e Vale do Paraíba Paulista para entender a força da dinâmica do mercado nesse processo e os motivos que afastam as mesmas instituições de ensino de demandas sociais que envolvam setores menos favorecidos.

Formar agentes produtores de processos e produtos tecnológicos implica em formar pessoas criativas e abertas a demandas diversificadas e as mesmas deverão estar presentes na dinâmica de formação prática.

\section{REFERÊNCIAS}

Braga, E., Dias, K., Sanches, K., Cardinot, D., Santos, A., Maroun, M., \& Braga, M. (2020). Cultura hacker no ambiente escolar: a disseminação da aprendizagem colaborativa e criativa. Research, Society and Development, 9(3). doi:http://dx.doi.org/10.33448/rsd$\underline{\mathrm{v} 9 \mathrm{i} 3.2663}$

Brekelmans M., et al. (2000). Teaching for Active Learning. In: Simons RJ., van der Linden J., Duffy T. (eds) New Learning. Springer, Dordrecht.

Christensen, C. M.(2001). O Dilema da Inovação: Quando novas tecnologias levam empresas ao fracasso. São Paulo: Makron Books.

Guimarães, A. (1999). Theodomiro Santiago. Belo Horizonte: Imprensa oficial.

Hayek, F. A. (2010). O Caminho da Servidão. $6^{\mathrm{a}}$ ed. São Paulo: Mises Brasil.

Konopka, C. L., et al. (2015). Active Teaching and Learning Methodologies: Some Considerations. Creative Education, 6, 1536-1545.

Motoyama, S. (Org.) (2004). Prelúdio para uma História: Ciência e Tecnologia no Brasil. São Paulo: Edusp.

Mcluhan, M. et al. (1968). War and Peace in the Global Village. NY: Bantam Book. 
Ponsa, P. et al. (2009). Higher Education Challenges: Introduction of Active Methodologies in Engineering Curricula. International Journal of Engineering Education, v.25, n.4, pp.799813.

Ribeiro, M.L.S. (1992). História da Educação Brasileira. 12ªed. São Paulo: Cortez.

Santos, N. C. G. et al. (2017). Ciência, Tecnologia e Sociedade na Iniciação Científica: O Caso de uma Universidade do Sul de Minas. Perspectivas Contemporâneas, v. 12, n. 3, p. 1732, set./dez.

Santos, M.; Silveira, M. L. (2001). O Brasil: Território e Sociedade no início do Século XXI. São Paulo e Rio de Janeiro: Record.

Saviani, D. (2011). História das Ideias Pedagógicas no Brasil. $3^{\mathrm{a}}$ ed. Campinas: Autores Associados.

Schultz, T. (1973). Capital Humano. Rio de Janeiro: Zahar.

Schumpeter, J. A. (1985). Teoria do Desenvolvimento Econômico. $2^{\mathrm{a}}$ ed. Os Economistas. São Paulo: Nova Cultural.

Seemiller C.; Grace, M. (2016). Generation Z Goes to College. San Francisco CA: Jossey Bass.

Vasconcelos, F., Pontes, M., \& Feitosa, R. (2020). Utilização do enfoque Ciência Tecnologia e Sociedade: Uma abordagem dinâmica e lúdica numa perspectiva de aprendizagem significativa no ensino fundamental. Research, Society and Development, 9(2), e97922108. doi:http://dx.doi.org/10.33448/rsd-v9i2.2108

\section{Porcentagem de contribuição de cada autor no manuscrito}

Benerina Porfirio Branco - 50\%

Adilson da Silva Mello - 50\% 